\section{Atos de fala diretivos em português e em espanhol: uma análise acústica comparativa}

Directive speech acts in portuguese and spanish: $a$ comparative acoustic analysis

Carolina GOMES DA SILVA (UFPB) carolinagsufpb@gmail.com

Manuella CARNAVAL (UFRJ) manuellacarnaval@gmail.com João Antônio de MORAES (UFRJ) jamoraes3@gmail.com

Recebido em: 30 de out. de 2019. Aceito em: 23 de jan. de 2020.
GOMES DA SILVA, Carolina;

CARNAVAL, Manuella; MORAES, João

Antônio de. Atos de fala diretivos em português e em espanhol: uma análise acústica comparativa. Entrepalavras Fortaleza, v. 10, n. 1, p. 326-345, janabr/2020. DOI: $10.22168 / 2237-6321-$

\section{1.}

Resumo: Este artigo descreve foneticamente os contornos melódicos de três atos de fala diretivos (ordem, pedido e súplica) em português do Brasil e em espanhol de variedade mexicana. Para tanto, foi utilizado um corpus de fala atuada, com a seleção de enunciados com a entoação dos três atos diretivos em cada língua. Em seguida, houve a aplicação de testes auditivos para o reconhecimento da intenção do locutor, bem como para a legitimação de sua performance, além de uma análise acústica para a caracterização do padrão entonacional de cada ato. Os resultados sugerem que a entoação pode constituir um dos mecanismos para a distinção dos três tipos de atos de fala diretivos, devido a diferenças entonacionais na produção de cada ato nas duas línguas analisadas.

Palavras-chave: Entoação dos atos de fala diretivos. Espanhol mexicano. Português do Brasil. 
Abstract: This paper describes phonetically the melodic contours of three directive speech acts (order, request and supplication) in Brazilian Portuguese and in Mexican Spanish variety. Therefore, an acted speech corpus was used, selecting utterances with the intonation of the three directive acts in each language. Perceptual tests were taken to recognize the speaker's intention as well as to legitimize his performance. Furthermore, an acoustic analysis was developed to characterize the intonational pattern of each act. The results suggest that intonation may be one of the mechanisms for distinguishing the three types of directive speech acts, due to intonational differences in the production of each act in both languages.

Keywords: Directive speech acts intonation. Mexican Spanish. Brazilian Portuguese.

\section{Introdução}

Os estudos dos atos de fala tiveram sua origem na filosofia da linguagem, a partir da obra de Austin, "How to do things with words". Nesse livro, Austin refuta a visão que colocava as condições de verdade como centrais para a compreensão da linguagem, uma vez que a muitos enunciados não se aplica a dicotomia verdadeiro ou falso, como as perguntas ou as ordens. Dessa maneira, Austin introduz as bases de uma teoria sobre os atos de fala.

Em Kerbrat-Orecchioni (2005, p. 27), é apontado que Searle, bem como Austin, considera que qualquer "enunciado linguístico funciona como um ato particular (ordem, pergunta, promessa, etc.), isto é, que ele visa a produzir um certo efeito e a implicar uma certa modificação da situação interlocutiva". A taxonomia proposta por Searle (1995) distingue cinco categorias para os atos ilocutórios, a saber: (i) assertivos, (ii) diretivos, (iii) promissivos, (iv) expressivos e (v) declarativos. O objetivo de cada uma destas cinco categorias pode ser resumido na seguinte citação:

Se adotamos o propósito ilocucionário como a noção básica para a classificação dos usos da linguagem, há então um número bem limitado de coisas básicas que fazemos com a linguagem: dizemos às pessoas como as coisas são, tentamos leválas a fazer coisas, comprometemo-nos a fazer coisas, expressamos nossos sentimentos e atitudes, e produzimos mudanças por meio de nossas emissões. (SEARLE, 1995, p. 46, grifo nosso).

Os atos de fala podem ser individualizados no fluxo da fala com base na prosódia. Também pela prosódia somos capazes de interpretar seus significados, o que ressalta a ideia de que um enunciado pode não ser definido apenas pela sua estrutura morfossintática, mas necessita também de sua forma prosódica (RASO, 2012). Além disso, a diversidade de situações comunicativas favorece a variedade de atos de fala diferentes. 
V. 10 (1)

$326-345$ jan-abr 2020

A entoação é citada, já em Searle (1969), como um dos mecanismos usados na distinção de diferentes tipos de atos. No português do Brasil, na ausência de outros índices, a entoação distingue vários atos diretivos, entre os quais: ordem, pedido, súplica, sugestão, desafio e conselho (MORAES, 2011).

Segundo Cresti (2000), a associação de um contorno prosódico a uma ilocução édefinida como critério ilocutivo. A marcação prosódica, então, denunciaria os limites do enunciado e, assim, permitiria sua identificação. Portanto, a prosódia constituiria uma interface entre o nível pragmático, dos atos de fala, e o nível linguístico, do enunciado (MITTMANN, 2012).

Como mencionado anteriormente, os atos de fala diretivos correspondem a uma das cinco classes de atos possíveis e se caracterizam pragmaticamente como uma tentativa, por parte do falante, de fazer com que o ouvinte venha a realizar uma ação (SEARLE, 1995; VANDERVEKEN, 1990). A distinção entre os atos de ordem, pedido e súplica, por exemplo, reside, segundo Vanderveken (op. cit.), no modo de realização do ato pelo falante, ao manifestar seu desejo de que determinada ação seja executada pelo ouvinte, que supõe uma posição de autoridade do falante, no caso da ordem, ausente no pedido e na súplica. No pedido, teríamos um modo polido e, na súplica, um modo que implica uma posição hierarquicamente inferior, subalterna. Além disso, a oposição entre súplica e os outros dois atos se respalda ainda no fato de o grau de força da "condição de sinceridade" (Searle, op. cit.) - o desejo que o locutor tem de que a ação seja executada pelo interlocutor - ser maior, ou mais intenso, na súplica do que na ordem ou no pedido, o que seria, segundo esses autores, tipicamente manifesto pela entoação.

Estudos já realizados para o português brasileiro, como os de Moraes (2008), Moraes e Rilliard (2018) e Raso et al. (2007), confirmam que a entoação é um dos mecanismos utilizados para distinguir os atos de fala, o que, naturalmente, deve se refletir nas distintas representações fonológicas desses atos. Neste trabalho, pretendemos descrever os contornos melódicos desses três atos diretivos (ordem, pedido e súplica) em português brasileiro (variedade carioca) e em espanhol (variedade da Cidade do México).

\section{Descrição da Entoação}

Alinhando-nos com Barbosa (2019, p. 67), entendemos por entoação "a organização na cadeia da fala de padrões de variação de graves e agudos ao longo dos enunciados". A entoação stricto sensu 
é descrita através da análise do contorno melódico (ou curva de Fo), embora as variações de duração também participem eventualmente da expressão de sentidos tradicionalmente atribuídos à entoação.

Para o mapeamento dos elementos distintivos da entoação, podemos lançar mão de teorias e modelos que auxiliam a compreender como a entoação é produzida e percebida pelos falantes. O modelo autossegmentalmétrico (doravante, AM), de Pierrehumbert (1980), por exemplo, tem como objetivo identificar os elementos contrastivos do sistema entonacional que produzem os contornos melódicos dos possíveis enunciados de uma língua (HUALDE, 2003). As distintas melodias que integram um enunciado são descritas a partir de uma sequência de dois tons, a saber: um tom alto $(\mathrm{H})$ e um tom baixo (L). Tais tons compõem os acentos tonais, movimentos ao redor das sílabas tônicas e indicados pelo símbolo de asterisco (*), e aos tons de fronteira, movimentos melódicos situados no limite da frase entonacional ou do enunciado, representados pelo símbolo de porcentagem (\%).

Tendo raízes no modelo AM, o sistema ToBI - Tones and Break Indices, foi pensado como um tipo estandardizado de etiquetagem prosódica para transcrição entonativa do inglês norte-americano e pode ser utilizado para a descrição prosódica de distintas línguas, incluindo a língua espanhola, quando recebe o prefixo Sp_ToBI. Neste trabalho, utilizamos a proposta do Sp_ToBI de Aguilar et alii. (2009), a qual propõe sete tipos de acentos tonais, a saber: dois monotonais, $\mathrm{H}^{*}$ e $\mathrm{L}^{*}$, e cinco bitonais, $\mathrm{H}+\mathrm{L}^{*}, \mathrm{~L}^{*}+\mathrm{H}, \mathrm{L}+\mathrm{H}^{*}, \mathrm{~L}+\mathrm{jH}^{*}$ e $\mathrm{L}+>\mathrm{H}^{*}$. O sistema de notação Sp_ToBI propõe também sete tons de fronteira de frases entoacionais associados ao limite de um enunciado. São estes: dois monotonais, L\% e M\%; quatro bitonais, HH\%, HL\%, LH\% e LM\% e um tritonal, LHL\%.

Cabe destacarmos também a importância de considerar os códigos biológicos (GUSSENHOVEN, 2002) nos estudos da entoação, a saber: (i) código de frequência, que reinterpreta algumas características universais da entoação (expressivas ou informacionais) com base no tamanho da laringe (cordas vocais); (ii) código de esforço, que se refere à amplitude, maior ou menor, da variação de Fo no enunciado, relacionada ao esforço vocal empregado pelo falante e (iii) código de produção, que se associa à variação decrescente da pressão de ar subglótica ao longo do enunciado, causando a linha de declínio da Fo. Juntos, esses códigos explicam o que é universal na interpretação do significado entonacional. Moraes e Rilliard (2018), por exemplo, demonstram que alguns atos de fala no português brasileiro podem ser diferenciados em termos de poder, imposição ou dominância, em conformidade com os códigos biológicos. 
V. 10 (1) $326-345$ jan-abr 2020

330

\section{Corpus e métodos}

Para desenvolvermos os objetivos propostos na introdução deste trabalho, partimos da hipótese de que a entoação será um mecanismo linguístico utilizado pelos falantes na distinção dos atos diretivos nas duas variedades analisadas: português brasileiro e espanhol mexicano (doravante $\mathrm{PB}$ e EM, respectivamente).

Assim, propomos uma descrição prosódica comparativa entre os atos de fala diretivos nessas duas variedades. Para a análise a partir do parâmetro acústico de frequência fundamental (Fo), procedemos à elaboração de um corpus com enunciados de fala atuada, pronunciados com material textual de maior extensão, 6 sílabas, e de menor extensão, com 3 sílabas (cf. quadro 1), gravados por um informante feminino, no caso do PB (falante da variante do Rio de Janeiro), e por um informante masculino, no caso do EM (falante da variante da cidade do México).

Quadro 1- Atos de fala produzidos pelos informantes da pesquisa

\begin{tabular}{|c|c|c|}
\hline Extensão & PB & EM \\
\hline 6 sílabas & Destranca a gaveta & Apaga la tele \\
\hline 3 sílabas & Destranca & Camina \\
\hline Fonte: Autoria própria.
\end{tabular}

Portanto, nosso corpus é constituído por 6 enunciados para cada língua aqui analisada ( 2 sentenças $\mathrm{x} 3$ atos de fala), perfazendo um total de 12 enunciados.

Em seguida, procedemos à aplicação de testes auditivos de reconhecimento da intenção e validação do desempenho dos locutores. Tais testes foram aplicados com 20 juízes brasileiros e 15 mexicanos, que, após a audição de cada enunciado em sua língua materna, deveriam indicar se correspondia a uma ordem, a um pedido ou a uma súplica.

Após essa etapa, os enunciados foram submetidos ao programa computacional PRAAT (BOERSMA; WEENINK, 1993-2016), o qual permitiu analisar o contorno e valores de Fo de todos os enunciados, incluindo os que foram mal reconhecidos, bem como segmentar manualmente cada um dos enunciados, para que fosse possível realizar, comparativamente entre português e espanhol, a descrição fonética e propor uma notação fonológica para cada enunciado. Seguindo as propostas do sistema ToBI, elaboramos uma lista de representações tonais para os atos diretivos, visto que, através deste modelo, é possível representar os diferentes tipos de contornos melódicos. 
Por fim, nossa análise também foi conjugada aos resultados do teste perceptivo, para o estabelecimento de conclusões e confirmação de nossa hipótese.

Na próxima seção, apresentamos as análises e as discussões dos nossos dados.

\section{Análise dos dados}

Nesta seção, apresentamos a análise dos dados desta pesquisa: primeiramente, tecemos considerações sobre os resultados do teste de percepção e, em seguida, discutimos as análises referentes às produções acústicas dos atos de fala em PB e em EM.

O teste perceptivo

Como já mencionamos, aplicamos testes auditivos de reconhecimento da intenção dos locutores, validando, assim, o desempenho dos locutores com base na avaliação de 20 juízes brasileiros e 15 mexicanos, que, após a audição de cada enunciado em sua língua materna, deveriam indicar se correspondia a uma ordem, a um pedido ou a uma súplica.

Com relação ao português do Brasil, o teste perceptivo apontou, em geral, altas taxas de reconhecimento para os três atos diretivos em questão, com exceção do ato de pedido, quando este é realizado em enunciado de extensão de 3 sílabas. Os enunciados foram avaliados por falantes cariocas com nível superior completo ou em andamento. O gráfico 1 detalha os percentuais de reconhecimento para cada ato de fala nas duas dimensões contempladas em nosso corpus, enunciados de 3 e 6 sílabas: 
V. $10(1)$ $326-345$ jan-abr 2020
Gráfico 1 - Índice de reconhecimento dos atos diretivos de duas extensões (3 e 6 sílabas) no PB: no eixo horizontal, os tipos de atos e, no eixo vertical, os valores em porcentagem das identificações corretas pelos juízes

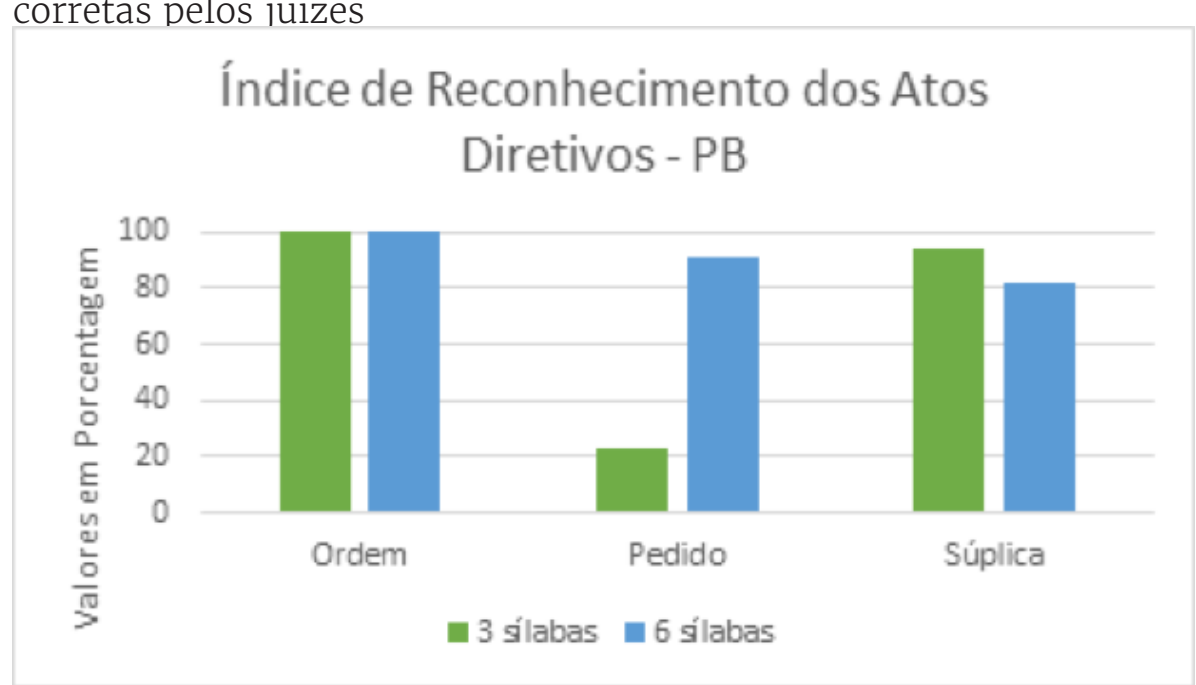

Fonte: Autoria própria.

Ao observar especificamente a ordem, pode-se perceber que este ato diretivo obteve reconhecimento de 100\% nas duas extensões de enunciados contempladas. Este elevado percentual de percepção por parte dos juízes nos permite concluir que o padrão melódico da ordem é robusto no $\mathrm{PB}$, apresentando bom reconhecimento independentemente do número de sílabas que o comportam.

A manutenção da funcionalidade dos padrões, a despeito da extensão do enunciado, também é verificada para a súplica, ainda que com índices um pouco mais baixos. Assim, apesar de obter maior reconhecimento em enunciado de 3 sílabas (94\%), a súplica também é consideravelmente bem identificada no enunciado de maior extensão (82\%).

Os resultados para o pedido, no entanto, mostram que, ao contrário do que ocorre nos outros dois tipos de ato, a identificação da intenção do falante, no enunciado mais curto, fica bastante prejudicada: ela cai de 91\% no enunciado de 6 sílabas para apenas 23\% no enunciado de 3 sílabas.

Por sua vez, na variedade da Cidade do México, o teste perceptivo foi aplicado com 15 juízes, todos mexicanos dessa cidade, de ambos os sexos, com nível superior completo ou em curso e idade entre 20 e 50 anos. Os resultados do teste de reconhecimento estão detalhados no gráfico 2. 
Gráfico 2 - Índice de reconhecimento dos atos diretivos de duas extensões (3 e 6 sílabas) no espanhol mexicano: no eixo horizontal, os tipos de atos e, no eixo vertical, os valores em porcentagem das identificações corretas pelos juízes

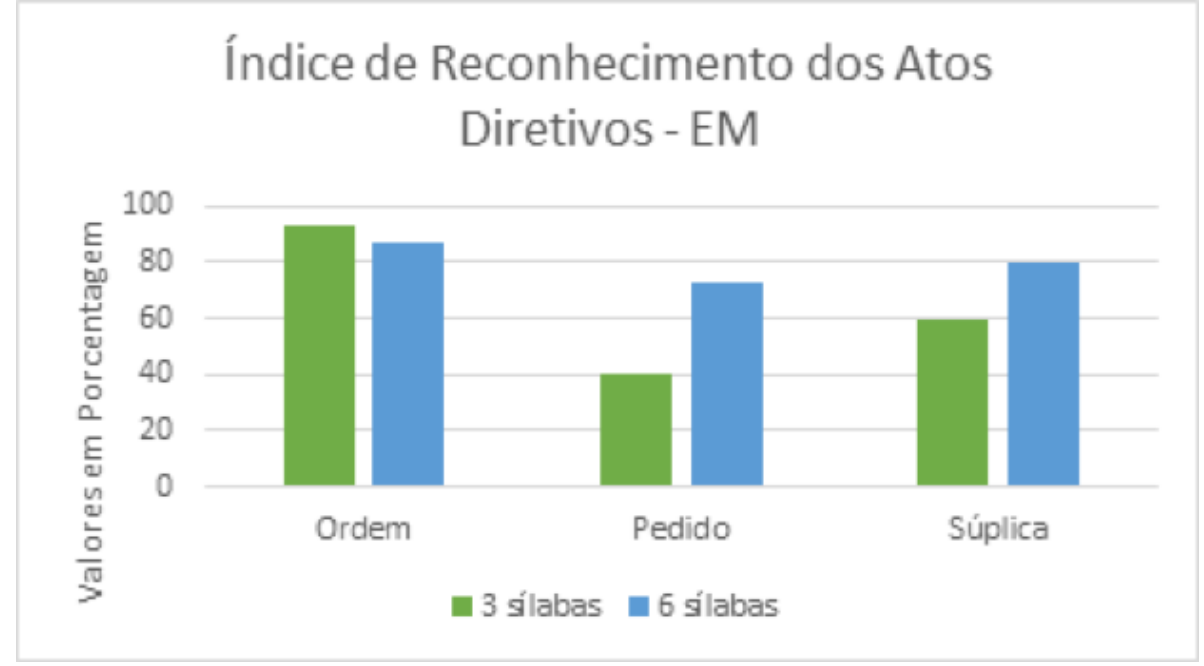

Fonte: Autoria própria.

Os contornos do ato diretivo de ordem foram bem identificados nas duas extensões silábicas. Tanto nos enunciados de maior extensão (6 sílabas), quanto nos enunciados nos de menor extensão (3 sílabas), a taxa de reconhecimento ultrapassou $85 \%$.

O contorno da súplica foi o segundo melhor identificado pelos 15 juízes que participaram do teste. A maior taxa de reconhecimento se apresenta nos enunciados de 6 sílabas: 87\%. Já, no enunciado de 3 sílabas, a taxa de reconhecimento foi de $60 \%$. Assim, para a súplica, a redução na extensão silábica do enunciado interferiu de forma expressiva na identificação do ato de fala, embora o índice de reconhecimento seja bom nos dois tipos de enunciados, o que abordaremos, mais adiante, em uma análise comparativa entre as duas variedades.

O pedido, por sua vez, apresentou taxa de reconhecimento de $73 \%$, no enunciado de 6 sílabas de extensão. No entanto, no enunciado de 3 sílabas, a taxa de reconhecimento caiu para $40 \%$.

Confrontando as duas variedades analisadas, podemos concluir que os resultados do teste perceptivo revelam que os três atos de fala diretivos foram muito bem ou bem reconhecidos, com exceção do ato de pedido, que se mostrou sensível à extensão silábica, apresentando importante diminuição nos índices de reconhecimento nos enunciados curtos. 
V. 10 (1) $326-345$ jan-abr 2020

Análise acústica

Nesta seção, ilustramos os contornos dos atos diretivos de ordem, pedido e súplica, no português do Brasil e no espanhol mexicano. Cabe lembrar que, nos enunciados muito curtos, pode ocorrer compressão, ou eventualmente truncamento do padrão melódico, o que pode comprometer seu reconhecimento (cf. MORAES; COLAMARCO, 2008; FROTA et alii., 2015).

Vejamos as análises dos nossos dados, a seguir.

Português do Brasil

Os atos diretivos apresentam, em sua maioria, contornos melódicos bastante distintos no $\mathrm{PB}$, como demonstrado no trabalho de Moraes (2008), a partir da descrição fonética de seis atos diretivos: ordem, desafio, pedido, súplica, sugestão e conselho. Nossa análise contempla enunciados produzidos com força ilocutória de ordem, pedido e súplica, descritos, a seguir, para o português do Brasil.

Figura 1 - Contorno melódico da ordem, na variedade carioca, produzido pela informante do sexo feminino

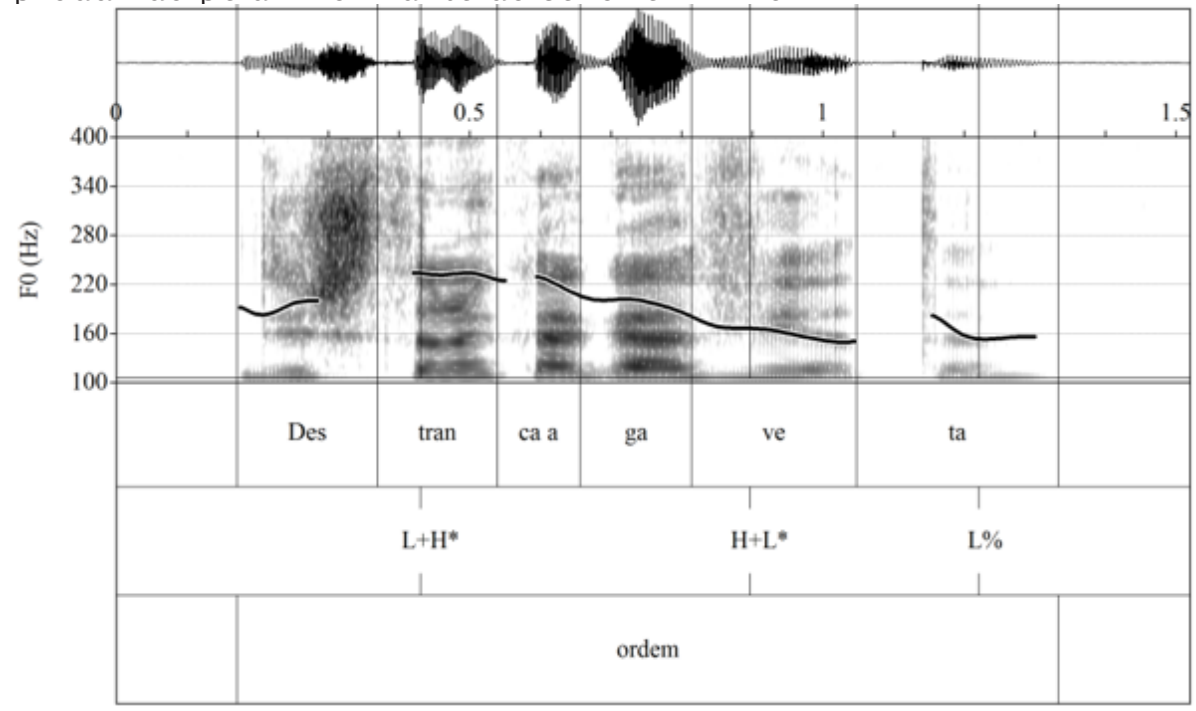

Fonte: Autoria própria.

O contorno melódico da figura 1 corresponde ao enunciado pronunciado como ordem no PB em nosso corpus. Sua curva de Fo apresenta um ataque alto, seguido por queda ao longo do enunciado e atingindo, por fim, um tom baixo sobre a tônica final, seguido de tom de fronteira também baixo, corroborando a descrição de Moraes (2008). Fonologicamente, a ordem apresenta a seguinte configuração tonal: $\mathrm{L}+\mathrm{H}^{*}$, para o pré-núcleo, e $\mathrm{H}+\mathrm{L} * \mathrm{~L} \%$, para a posição nuclear. 
Consideramos o pré-núcleo como o vocábulo que inclui a primeira sílaba tônica do enunciado e núcleo, o que contém a última sílaba tônica; nesse caso, "destranca" e "gaveta", respectivamente.

O pedido se caracteriza também por um ataque melódico alto seguido pela queda de Fo. A região pré-nuclear costuma se apresentar mais alta em relação ao pré-núcleo da ordem, como pode ser observado na comparação entre as figuras 1, relativa ao contorno da ordem, e 2, relativa ao contorno do pedido. No entanto, a distinção do pedido em relação ao contorno da ordem encontra-se, sobretudo, no núcleo, caracterizado pelo movimento melódico circunflexo com alinhamento antecipado do pico de Fo. Portanto, o nível melódico mais alto do prénúcleo no pedido poderia ser interpretado como um traço redundante, não propriamente distintivo, e, dessa forma, não fonológico.

Assim, a notação fonológica para o pedido apresenta a mesma configuração pré-nuclear que a da ordem, $\mathrm{L}+\mathrm{H}^{*}$, diferenciando-se em posição nuclear com a seguinte notação L+>H*L\%1 (MORAES, 2008), como observado na figura 2 :

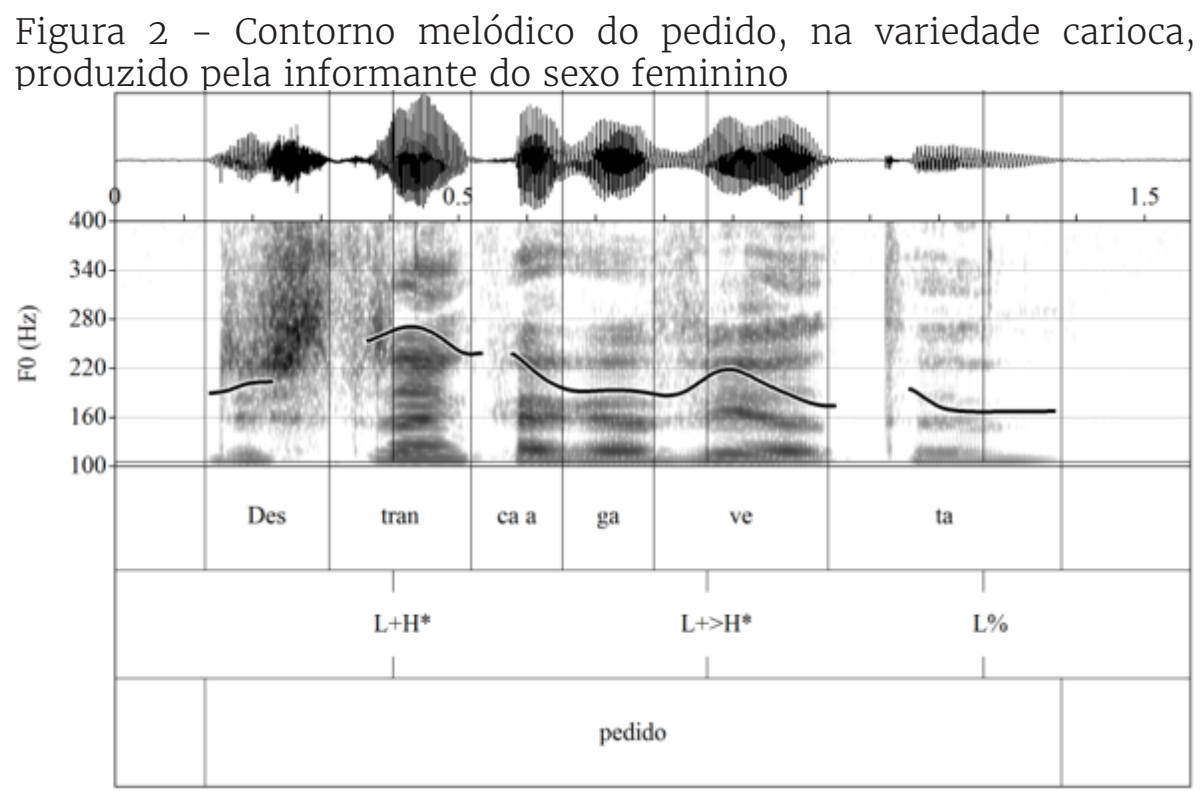

Fonte: Autoria própria.

Por fim, a súplica, cujo contorno melódico é ilustrado na figura 3, se distingue dos demais atos diretivos aqui analisados pelo aumento expressivo de duração da sílaba nuclear e pela presença de um pico melódico extra alto em posição pré-nuclear. Após este movimento

\footnotetext{
${ }^{1} \mathrm{O}$ símbolo >, neste trabalho, seguindo a notação de Moraes (2008), indica o alinhamento adiantado do pico de Fo. Se seguido o sistema Sp_ToBI, a notação para o núcleo em questão seria $\mathrm{L}+\mathrm{H} * \mathrm{~L} \%$, já que o símbolo $>$ em $\mathrm{L}+\mathrm{H} * \mathrm{~L} \%$ indicaria que o pico melódico é atingido na sílaba pós-tônica, o que não se aplica ao contorno da figura 3.
} 
V. $10(1)$ $326-345$ jan-abr 2020

característico na primeira tônica, observamos o declínio da Fo ao longo do enunciado até a pretônica final inclusive, sendo que, na tônica final, delineia-se um movimento circunflexo com alinhamento antecipado e fronteira baixa. Portanto, a representação fonológica da súplica consiste em $\mathrm{L}+\mathrm{jH}^{* 2}$ para o pré-núcleo, distinta dos enunciados anteriores. ${ }^{3}$

Para o núcleo, o contorno melódico da súplica apresenta comportamento semelhante ao do pedido, sendo também representado por $\mathrm{L}+>\mathrm{H} * \mathrm{~L} \%$. A diferença em posição nuclear entre os dois atos diretivos se manifestará no PB pelo alongamento expressivo da sílaba tônica nuclear da súplica, que tem uma duração cerca de $40 \%$ superior à do pedido.

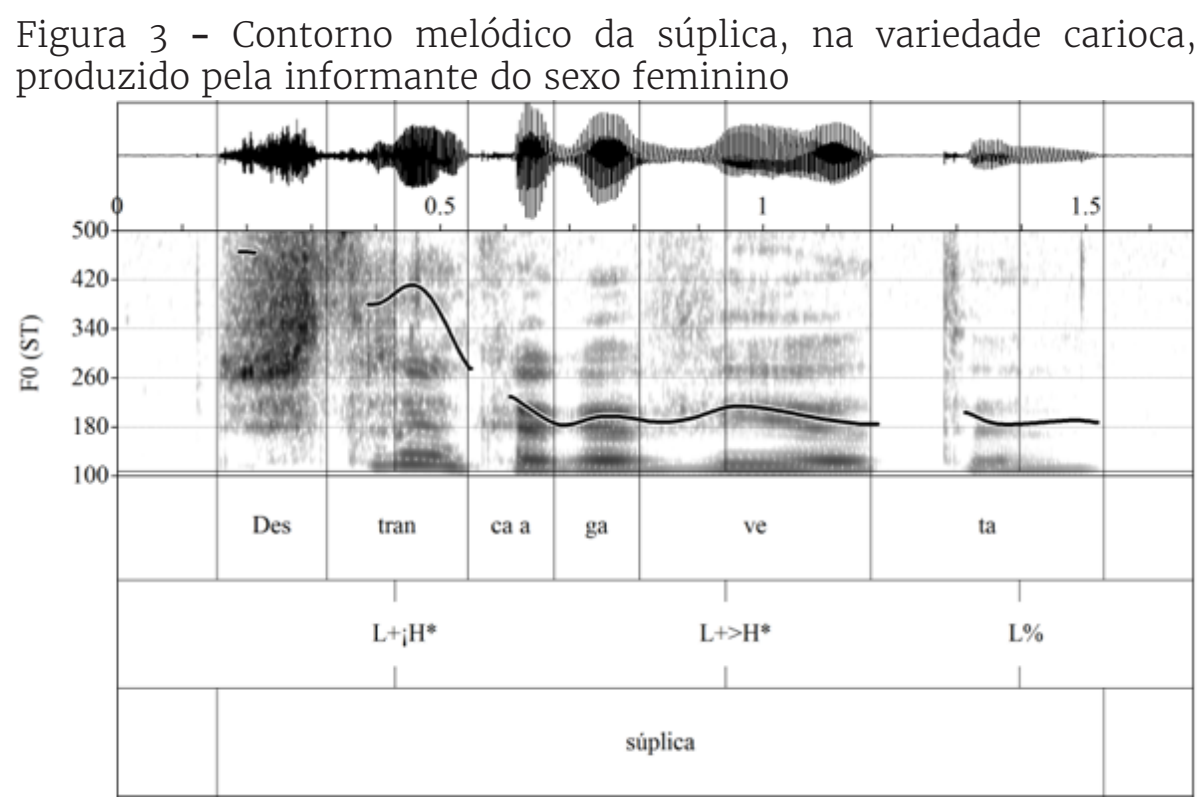

Fonte: Autoria própria.

Dessa forma, pedido e súplica se singularizam no português do Brasil a partir de dois traços acústicos, a saber: (i) a altura da Fo em posição pré-nuclear, que marca um nível extra-alto na súplica, $\mathrm{L}+j \mathrm{H}^{*}$, em oposição ao nível alto no pedido, $\mathrm{L}+\mathrm{H}^{*}$, e (ii) a duração, que se apresenta, em posição nuclear, expressivamente superior no ato de súplica em comparação ao ato de pedido.

Em relação aos enunciados de menor extensão (3 sílabas), no PB, podemos observar, na figura 4, para o contorno da ordem, uma compressão do padrão melódico encontrado no enunciado de maior extensão (6 sílabas). Mantém-se, assim, o ataque alto $(\mathrm{H})$ sobre a primeira sílaba, nesse caso, pretônica, atingindo tom baixo ao final do enunciado ( $\mathrm{H}+\mathrm{L} * \mathrm{~L} \%)$.

${ }^{2} \mathrm{O}$ símbolo i antecedendo o $\mathrm{H}$ representa um tom extra-alto verificado no pré-núcleo.

${ }^{3}$ Em Moraes (2011), o acento pré-nuclear da súplica foi representado por $j \mathrm{~L}+j \mathrm{H}^{*}$, implicando que esse acento era globalmente deslocado para cima; optamos aqui pela notação $\mathrm{L}+\mathrm{jH}^{*}$ por ser ela mais econômica e por ser, sobretudo, na tônica que se evidencia esse deslocamento. 
Já para os atos de pedido e súplica, são, em princípio, necessárias duas sílabas tônicas, para que o padrão prototípico se realize plenamente, como apontado em Moraes e Colamarco (2008). Por conta da falta de uma das tônicas, há uma neutralização da distinção entre ordem e pedido, apresentando, sobretudo esse último, baixo reconhecimento em enunciado de 3 sílabas. No caso da súplica, essa ausência seria compensada pelo alongamento vocálico.

Figura 4 - Contornos melódicos da frase "Destranca", dita como ordem (à esquerda), pedido (ao centro) e súplica (à direita) na variedade carioca, produzidos pelo informante do sexo feminino
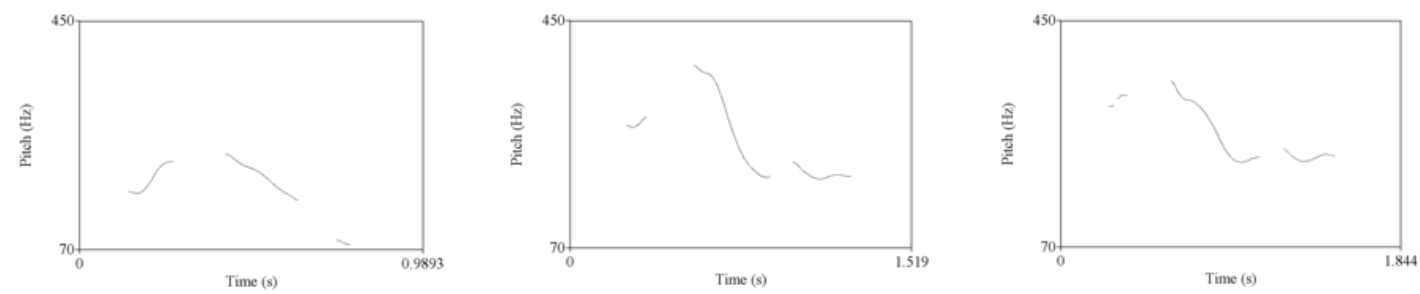

Fonte: Autoria própria.

Como apresentado na seção anterior, com exceção do pedido de menor extensão, os atos diretivos aqui analisados apresentam elevado percentual de reconhecimento no $\mathrm{PB}$, indicando que os três atos apresentam estruturas prosódicas bastante robustas.

\section{Espanhol Mexicano}

Alguns trabalhos já mencionam diferenças entre a entoação declarativa (sem marcas de expressividade) e a chamada "entoação imperativa" (cf. NAVARRO TOMÁS, 1974; WILLIS, 2002), subgrupo que abrangeria os atos de ordem, pedido e súplica. Navarro Tomás (1974), por exemplo, sugere que o tom seria um dos parâmetros utilizados para diferenciar a entoação declarativa da imperativa. Além disso, a interpretação do ouvinte da força apelativa da mensagem dependeria tanto da entoação quanto da velocidade de elocução, da intensidade e do registro tonal utilizado pelo falante (RAE, 2011).

Com efeito, observamos nos estudos sobre os atos de fala diretivos em espanhol, majoritariamente, pesquisas que comparam a prosódia de enunciados imperativos - com função pragmática de ordem - e declarativos, com o objetivo de encontrar pistas acústicas que distingam tais tipos de frases. No caso do espanhol mexicano, as investigações estabelecem diferenças acústicas entre os dois tipos de enunciados, tais como: na ordem, (i) maior uso do alinhamento 
V. 10 (1) $326-345$ jan-abr 2020

antecipado no acento pré-nuclear; (ii) redução da desacentuação; (iii) maior campo tonal e (iv) aumento da duração (WILLIS, 2002). Mais especificamente para a variedade de espanhol da Cidade do México, De-La-Mota et alii. (2010) também analisam enunciados proferidos como ordem e súplica (em espanhol, ruego). Os autores descrevem dois contornos distintos para cada um desses atos, o que corrobora a hipótese de que a entoação constituiria um elemento acústico de distinção entre atos diretivos, bem como entre enunciados declarativos e imperativos.

No caso dos enunciados curtos, Brehm et alii. (2014) e Lausecker et alii. (2014) analisam enunciados proferidos como ordem, produzidos por falantes de três cidades mexicanas: Torreón, Mexicali e Monterrey. Ambos os trabalhos abordam a variável extensão do enunciado, por isso verificam as características prosódicas (i) em frases curtas, compostas por um único verbo e (ii) em frases longas, com verbo imperativo na posição inicial da frase, coincidindo com o acento pré-nuclear. Os resultados demonstram, para as frases curtas, acento nuclear ascendente ou alto, com fronteira baixa $-(\mathrm{L}+) \mathrm{H} * \mathrm{~L} \%$.

Em nossos dados, verificamos, para o contorno da ordem, que a curva melódica é marcada por um movimento ascendente na sua parte pré-nuclear e por um movimento descendente na sua parte nuclear (figura 5). Nesse caso, há um ataque melódico ascendente com manutenção do contorno no nível alto até a sílaba pré-tônica nuclear, onde tem início o movimento descendente que se estende até a fronteira do enunciado. Propomos, portanto, a notação $\mathrm{L}+\mathrm{H}^{*}$, para o pré-núcleo, e $\mathrm{H}+\mathrm{L}^{*} \mathrm{~L} \%$, para o núcleo.

Figura 5 - Contorno melódico da ordem, na variedade mexicana (Cidade do México), produzido pelo informante do sexo masculino

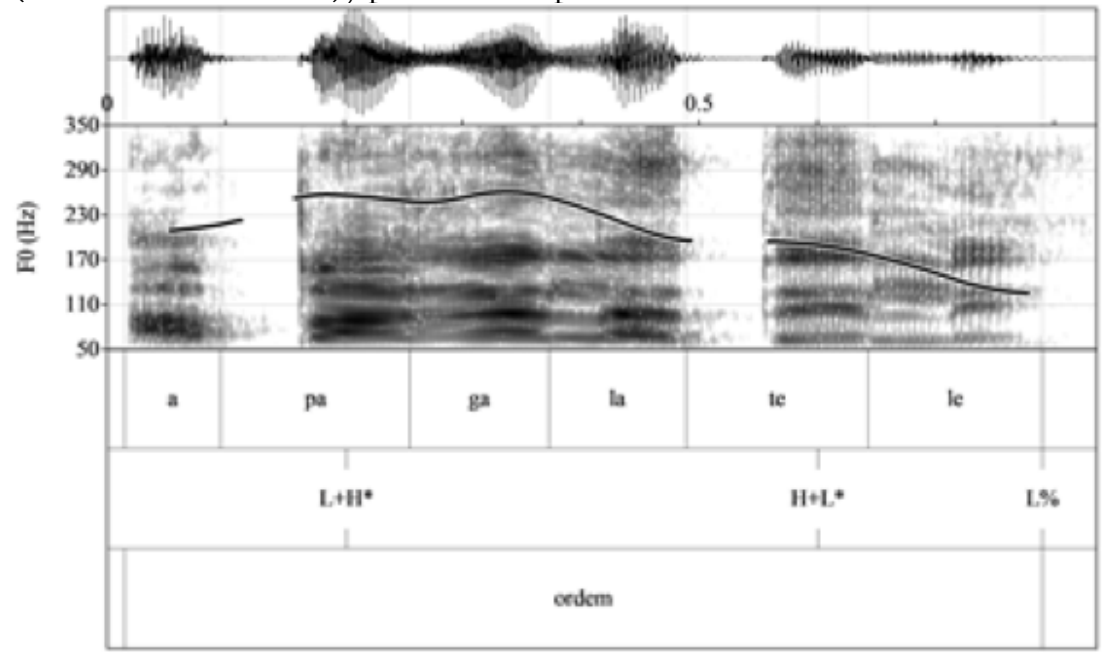

Fonte: Autoria própria. 
Para o contorno do pedido, observamos, globalmente, um ataque ascendente seguido de descida da Fo. Com relação à inflexão que ocorre no início do contorno, podemos sinalizar que o pico de Fo se encontra deslocado para a sílaba pós-tônica pré-nuclear. Assim, propomos a notação prosódica $\mathrm{L}+>\mathrm{H}^{*}$, para o pré-núcleo, e H+L*L\%, para o núcleo como ilustra a figura 6.

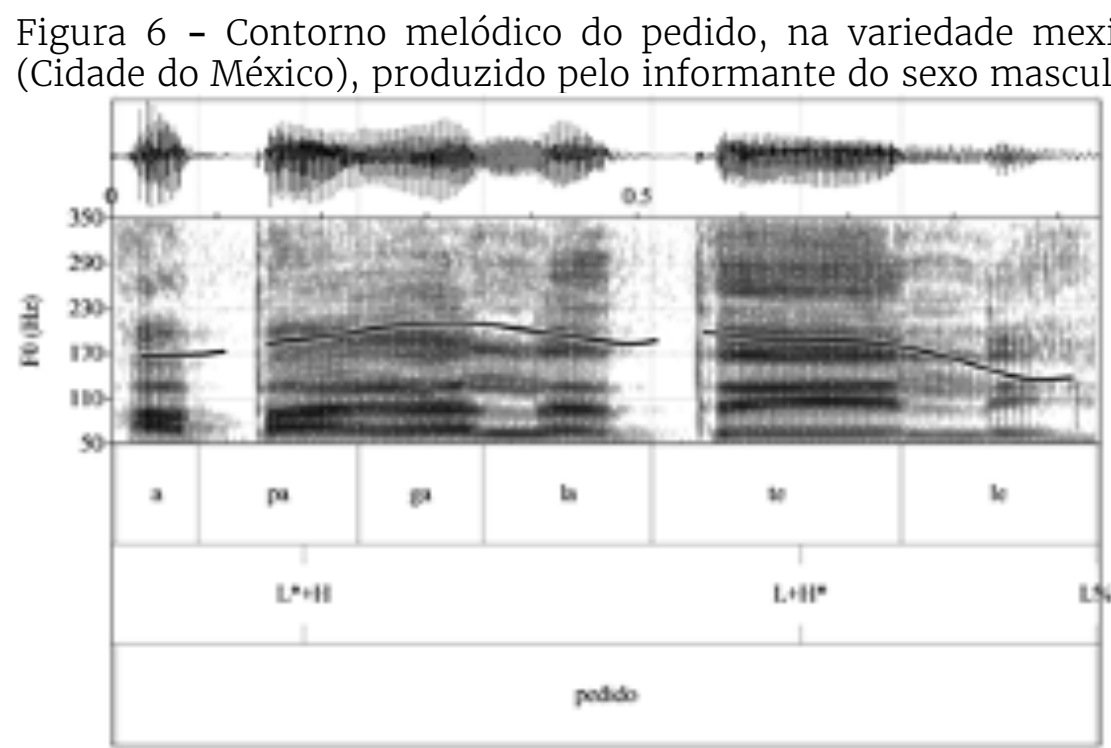

Fonte: Autoria própria.

Para a súplica, observamos, globalmente, no enunciado de 6 sílabas, um movimento ascendente na parte pré-nuclear do contorno melódico e um movimento circunflexo em sua parte nuclear. Ou seja, verificamos um ataque ascendente, seguido de descida de Fo, a que se segue uma nova subida na sílaba tônica nuclear. A fronteira final é descendente. Assim, propõe-se a notação prosódica $\mathrm{L}+\mathrm{H}^{*}$, para o prénúcleo, e $\mathrm{L}+\mathrm{H} * \mathrm{~L} \%$, para o núcleo, como ilustra a figura 7.

Figura 7 - Contorno melódico da súplica, na variedade mexicana (Cidade do México), produzido pelo informante do sexo masculino

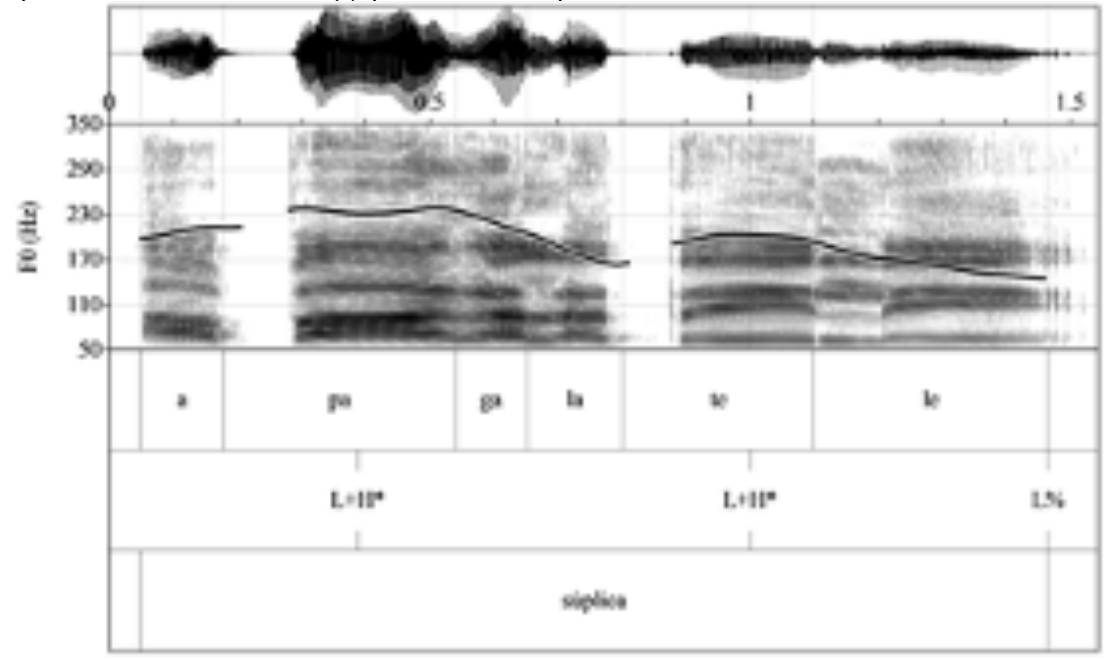

Fonte: Autoria própria. 
V. 10 (1) $326-345$ jan-abr 2020

Podemos perceber pela comparação entre a figura 5 e a figura 6, que os contornos melódicos da ordem e do pedido, neste informante da variedade mexicana, distinguem-se pelo alinhamento do pico de Fo na parte pré-nuclear: na ordem, alinha-se à sílaba tônica, ao passo que, no pedido, alinha-se à sílaba pós-tônica. Embora a notação fonológica nuclear seja a mesma, verificamos uma diferença no núcleo entre os dois atos diretivos que ocorre na implementação fonética, com o aumento expressivo de duração da sílaba nuclear no pedido em relação a esta mesma sílaba na ordem.

É possível constatarmos também que o alongamento das sílabas tônicas, tanto pré-nucleares quanto nucleares, é o que distingue o ato de súplica dos atos de ordem e pedido: maior na súplica e menor na ordem. Isso parece explicar o fato de que a súplica, ainda que confundida em certa medida com pedido e ordem, o tenha sido numa menor escala do que a confusão que se observa entre pedido e ordem. Além disso, há uma progressão na duração total do enunciado, variando do ato de ordem ao ato de súplica (ordem < pedido < súplica).

No que tange aos enunciados de 3 sílabas, ilustrados na figura 8, verificamos que possuem um padrão entonacional comum: um ataque mais baixo, uma subida interna e uma queda mais próxima do fim, ou seja, um padrão circunflexo. Ainda assim, do ponto de vista da implementação fonética, é possível distingui-los pelo alinhamento do pico na sílaba tônica bem como pelo comportamento da duração.

Figura 8 - Contornos melódicos da frase "Camina", dita como ordem (à esquerda), pedido (ao centro) e súplica (à direita) na variedade mexicana (Cidade do México), produzidos pelo informante do sexo masculino
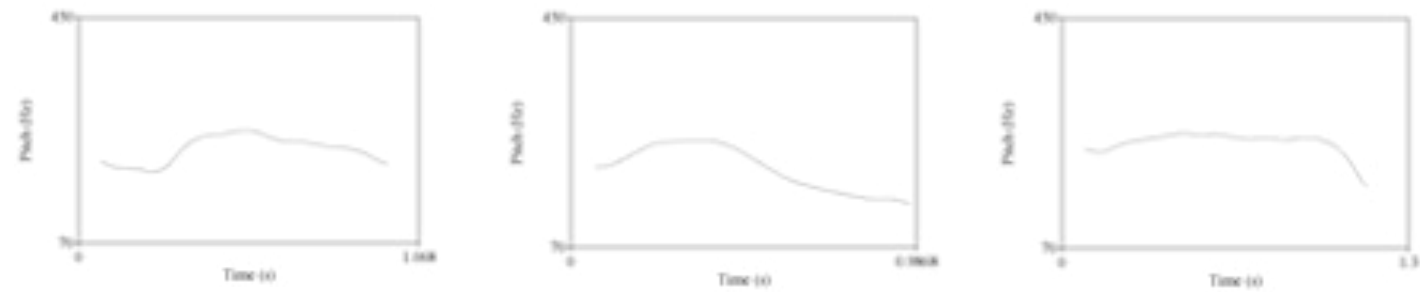

Fonte: Autoria própria.

O contorno melódico da ordem apresenta ataque alto com pico de Fo alinhado à sílaba tônica "mi", seguido de pequena descida, com notação $\mathrm{L}+\mathrm{H} * \mathrm{~L} \%$. No caso do pedido, verificamos um ataque melódico ascendente com pico de Fo alinhado à sílaba tônica, seguido de descida até a fronteira do enunciado, com notação $\mathrm{L}+\mathrm{H} * \mathrm{~L} \%$. $\mathrm{O}$ ato de pedido é bastante confundido com o de ordem, o que pode ser explicado pelo 
fato de os movimentos melódicos, depreendidos na análise acústica, serem bastante semelhantes nesses dois atos. Finalmente na súplica, o contorno de Fo se mantém alto até a sílaba final, com notação H*HL\%. Cabe destacarmos também que essa semelhança entre os contornos dos enunciados de três sílabas da variedade mexicana pode ter contribuído para os índices de reconhecimento mais baixos no teste perceptivo, como descrito na seção 0 teste perceptivo.

Como mencionado anteriormente, também destacamos o papel da duração na diferenciação entre esses atos: os valores de duração das sílabas pós-tônicas variam em uma escala ordem < pedido < súplica. Em outras palavras, verificamos que a duração dessas sílabas do ato de súplica é $37 \%$ mais longas que no ato do pedido, que, por sua vez, é $4 \%$ mais longa que no ato de ordem.

\section{Abordagem comparativa}

Observando os contornos melódicos dos atos de fala em cada variedade, podemos perceber que o português do Brasil, em sua variedade carioca, e o espanhol da Cidade do México se distinguem a partir de movimentos melódicos específicos nas posições pré-nuclear e nuclear. Assim, pedido e súplica são realizados prosodicamente de forma distinta nas duas línguas. Por outro lado, é possível verificarmos semelhanças no contorno melódico da ordem: tanto no português do Brasil quanto no espanhol da Cidade do México. Tal contorno se caracteriza por um ataque melódico alto, representado pelo movimento ascendente em posição pré-nuclear $\left(\mathrm{L}+\mathrm{H}^{*}\right)$, seguido da queda de Fo, que se delineia até o final do enunciado, caracterizado pelo movimento descendente no núcleo $\left(\mathrm{H}+\mathrm{L}^{*}\right)$ e a manutenção de um tom baixo em sua fronteira ( $\left.\mathrm{L}^{*}\right)$. Este padrão melódico é bem definido em ambas as variedades. Isto pode ser confirmado pelos elevados percentuais de identificação, que atingem 100\% de reconhecimento no português do Brasil e 93\% no espanhol da Cidade do México, considerando-se os enunciados de maior e menor extensão conjuntamente. Assim, o padrão melódico bem definido do ato diretivo de ordem é validado pelo alto reconhecimento perceptivo nas duas línguas.

Com relação ao pedido, os contornos melódicos do português do Brasil e do Espanhol da Cidade do México são caracterizados por movimentos distintos. No acento pré-nuclear, o pico melódico na variedade brasileira é atingido na sílaba tônica $\left(\mathrm{L}+\mathrm{H}^{*}\right)$, ao passo que, na variedade mexicana, ele ocorre na sílaba pós-tônica ( $\left.\mathrm{L}+>\mathrm{H}^{*}\right)$. Em posição 
V. $10(1)$

$326-345$ jan-abr 2020

nuclear, as duas variedades também apresentam comportamentos distintos. O português do Brasil se caracteriza por um contorno característico, o movimento circunflexo com alinhamento antecipado do pico de $\mathrm{Fo}\left(\mathrm{L}+>\mathrm{H}^{*} \mathrm{~L} \%\right)$. Confrontando a descrição acústica do ato de pedido com os resultados obtidos no teste perceptivo, podemos constatar que o contorno melódico deste ato é melhor reconhecido quando há mais espaço segmental para sua acomodação, já que atinge 91\% de reconhecimento no PB, nos enunciados de 6 sílabas, caindo para apenas $23 \%$, nos de 3 sílabas. Por sua vez, na variedade mexicana, verificamos um movimento descendente na posição nuclear $(\mathrm{H}+\mathrm{L} * \mathrm{~L} \%)$, semelhante ao movimento descrito para o ato de ordem.

Para a súplica, o PB apresenta a mesma modulação nuclear realizada para o pedido $(\mathrm{L}+>\mathrm{H} * \mathrm{~L} \%)$, indicando um movimento circunflexo, que também caracteriza o ato de súplica na variedade mexicana. Esta, no entanto, apresenta implementação diversa do movimento circunflexo nuclear $\left(\mathrm{L}+\mathrm{H}^{*} \mathrm{~L} \%\right)$. Com relação à posição prénuclear, enquanto a variedade mexicana do espanhol se caracteriza por ataque alto $\left(\mathrm{L}+\mathrm{H}^{*}\right)$, o PB é caracterizado por ataque extra-alto $\left(\mathrm{L}+\mathrm{jH}^{*}\right)$, o que parece ser distintivo para a variedade brasileira na manifestação deste ato diretivo em relação ao ato de pedido (com pré-núcleo $\mathrm{L}+\mathrm{H}^{*}$ ), em conjunto com o parâmetro acústico de duração, que se apresenta em posição nuclear expressivamente superior no ato de súplica em comparação à do pedido. Os padrões melódicos do ato de súplica em ambas as variedades são bem definidos, como apontam os altos percentuais de reconhecimento. Chama-nos a atenção que, no caso do $\mathrm{PB}$, diferentemente dos outros atos, o enunciado de menor extensão tenha apresentado taxa mais alta que o de maior extensão ( $94 \%$ e $82 \%$, respectivamente), indicando que a compressão do padrão melódico não prejudica o reconhecimento deste ato, o que pode ser associado ao ataque extra-alto característico da variedade carioca.

Por fim, com relação aos enunciados de menor extensão, em que há a compressão do padrão melódico, notamos que a análise fonológica AM tradicional, em apenas dois níveis, alto e baixo, teria dificuldades em dar conta das oposições, especialmente no português brasileiro: globalmente, todos os padrões receberiam uma mesma notação LHL (configuração circunflexa), isto é, um ataque mais baixo, uma subida interna e uma queda mais próxima do fim, na variedade carioca. Assim, teríamos de ter um sistema que considerasse detalhes fonéticos mais finos, como a inclinação da curva melódica e/ou distintos 
graus de subida melódica para dar conta das diferenças observadas. Já para a variedade mexicana, embora tenhamos verificado diferenças na implementação do contorno melódico, vale destacarmos o papel da duração na diferenciação dos atos.

Considerando os códigos biológicos, especialmente o de frequência (GUSSENHOVEN, 2002), é possível depreender que o ato de ordem, nas duas variedades analisadas, seria mais assertivo e dominante, já que os dados mostram um contorno descendente, que se encontra em um registro um pouco mais grave que o do pedido. A súplica, em contrapartida, como possui contorno com final marcado, isto é, núcleo circunflexo, seria um ato menos impositivo e, por estar majoritariamente em um registro agudo, estaria vinculado a um comportamento mais submisso, em ambas variedades. No que concerne ao pedido, podemos verificar uma diferença entre o PB e o EM: pelos contornos melódicos, este ato seria mais autoritário na variedade mexicana, já que apresenta contorno descendente como a ordem, diferentemente da variedade carioca, cujo contorno circunflexo poderia dar-nos pistas de que seria um ato menos autoritário em tal variedade.

\section{Conclusão}

A partir de nossa análise empírica e descritiva, podemos considerar que, em relação à extensão do enunciado, a expectativa é de que, com 6 sílabas, o reconhecimento seja bom, piorando à medida que se comprime o enunciado. De fato, observamos que, em geral, nos enunciados de 6 sílabas, o reconhecimento dos padrões é muito alto. Estes apresentam duas sílabas tônicas, permitindo, assim, uma adequação confortável do padrão melódico ao texto, especialmente nos padrões melódicos complexos, como os do pedido e da súplica, que, no caso da variedade carioca do português, realizam duas subidas melódicas nas tônicas e, portanto, "precisam" de, pelo menos, duas tônicas para acomodarem essas subidas, como já indicado por Moraes (2008) e Moraes e Colamarco (2008).

Observamos também que o ato de pedido no espanhol da Cidade do México, embora tenha índices de reconhecimento razoáveis, foi bastante confundido com a ordem e com a súplica, o que levanta a hipótese de que o ato de pedido poderia não apresentar diferenças tão evidentes do ponto de vista acústico nesta variedade, sendo utilizadas outras estratégias linguísticas para expressar esse ato. 
V. 10 (1) 326-345 jan-abr 2020

A descrição e comparação das variedades analisadas em nosso trabalho confirmam nossa hipótese de que a entoação é um mecanismo de diferenciação entre os atos diretivos de ordem, pedido e súplica nas duas línguas. Além disso, podemos afirmar que a realização prosódica desses atos de fala apresenta semelhanças, no caso do ato de ordem, e diferenças, para os atos de pedido e súplica, na variedade carioca e na variedade mexicana, indicando que as línguas guardam semelhanças melódicas entre si ao mesmo tempo em que dispõem de estratégias melódicas e/ou linguísticas distintas na produção de tais atos.

\section{Referências}

AGUILAR, L.; DE-LA-MOTA, C.; PRIETO, P. (coords). Sp_ToBI Training Materials. 2009. Disponível em: http://prosodia.upf.edu/sp_tobi/. Acesso em: 31 jan. 2020.

BARBOSA, P. A. Prosódia. São Paulo: Parábola, 2019.

BOERSMA, P.; WEENINK, D. Praat, 1993-2016. Disponível em: http://www.fon. hum.uva.nl/praat/.

BREHM, A.; LAUSECKER, A.; FELDHAUSEN, I. The Intonation of Imperatives in Mexican Spanish. In: FUSCHS, S.; GRICE, M.; HERMES, A.; LANCIA, L.; MÜCKE, D. (eds.) INTERNATIONAL SEMINAR ON SPEECH PRODUCTION, 10., 2014, Köln. Proceedings [...]. Köln (Germany), 2014. p. 53-56.

CRESTI, E. Corpus di Italiano parlato. Firenze: Accademia de lla Crusca, 2000.

DE-LA-MOTA, C.; BUTRAGUEÑO, P. M.; OROZCO, L.; PRIETO, P. "Mexican Spanish Intonation". In: PIETRO, P.; ROSEANO, P. (org.). Transcription of Intonation of the Spanish Language. München: Lincom Europa, 2010. p. 319-350.

FROTA, S.; CASTELO, J.; CRUZ, M.; BARROS, N.; CRESPO-SENDRA, V.; SILVESTRE, A. P. Melodia ou texto? Estratégias de acomodação entre melodia e texto no Português. Revista Diadorim, Rio de Janeiro, v.17, p. 12-33, 2015.

GUSSENHOVEN, C. Intonation and interpretation: Phonetics and Phonology. SPEECH PROSODY 2002: INTERNATIONALCONFERENCE ON SPEECH PROSODY, 1., Aix-en-Provence, 2002. Proceedings [...]. Aix-en-Provence: ProSig and Universit'e de Provence Laboratoire Parole et Langage, 2002. p. 47-57.

HUALDE, J. I. El modelo métrico y autossegmental. In: PRIETO, P. (coord.). Teorías de la entonación. Barcelona: Ariel, 2003. pp. 155-184.

KERBART-ORECCHIONI, C. Os atos de linguagem no discurso. Tradução: Fernando Afonso de Almeida e Irene Ernest Dias. Niterói: EdUFF, 2005.

LAUSECKER, A.; BREHM, A.; FELDHAUSEN, I. Intonational aspects of imperatives in Mexican Spanish. In: CAMPBELL, N.; GIBBON, D.; HIRST, D. (eds.) INTERNATIONAL CONFERENCE ON SPEECH PROSODY, 7., Dublin, 2014. Proceedings [...]. Dublin, 2014. p. 683-687. 
MITTMAN, M. O C-ORAL-BRASIL e o estudo da fala informal: um novo olhar sobre o Tópico no Português Brasileiro. 2012. 248 p. Tese (Doutorado em Linguística), Faculdade de Letras, Universidade Federal de Minas Gerais, Belo Horizonte, 2012.

MORAES, J. A. The pitch accents in Brazilian Portuguese: analysis by synthesis. In: SPEECH PROSODY, Campinas, 2008. Proceedings [...]. Campinas: Unicamp, 2008. p. 389-397.

MORAES, J. A. A entoação de atos de fala diretivos no PB. In: COLÓQUIO BRASILEIRO DE PROSÓDIA DA FALA, 3., Belo Horizonte, 2011. Resumo [...]. Belo Horizonte: FALE-UFMG, 2011.

MORAES, J. A.; COLAMARCO, M. Accommodation of intonational patterns in Brazilian Portuguese short utterances: compression or truncation? In: BISOL, L.; BRESCANCINI, C. R. Contemporary Phonology in Brazil. New England: Cambridge Scholars Publishing, 2008. pp. 2-21.

MORAES, J. A.; RILLIARD, A. Describing the intonation of speech acts in Brazilian Portuguese: methodological aspects. In: FELDHAUSEN, I.; FLIESSBACH, J.; VANRELL, M. M. (eds.). Methods in prosody: A Romance language perspective [Studies in Laboratory Phonology (SILP)]. Berlin: Language Science Press, 2018. p. 229-262.

NAVARRO TOMÁS, T. Manual de entonación española. 4.ed. Madrid: Ediciones Guadarrama, 1974 .

PIERREHUMBERT, J. B. The phonology and Phonetics of English Intonation. 402p. Tesis doctoral, MIT, Cambridge, Massachusetts, 1980.

RAE. REAL ACADEMIA ESPAÑOLA. Nueva gramática de la lengua española: Fonética y fonología. Barcelona: Espasa, 2011.

RASO, T. O C-ORAL-BRASIL e a teoria da língua em ato. In: RASO, T; MELLO, H. C-ORAL-BRASIL I: Corpus de referência do português brasileiro falado informal. Belo Horizonte: Editora UFMG, 2012.

RASO, T; MELLO, H.; JESUS, A.; DEUS, L. Uma aplicação da teoria da Língua em Ato ao português do Brasil. Revista de Estudos Linguísticos, Belo Horizonte, v. 15, n. 2, p. 147-166, jul./dez. 2007.

SEARLE, J. Speech Acts. An Essay in the Philosophy of Language. Cambridge: Cambridge University Press, 1969.

SEARLE, J. Expressão e significado: estudos da teoria dos atos de fala. Tradução: Ana Cecília de Camargo e Ana Luiza Marcondes. São Paulo: Martins Fontes, 1995. pp. 1-46.

VANDERVEKEN, D. Meaning and Speech Acts. Cambridge: Cambridge University Press, 1990. 1 V.

WILLIS, E. Is There a Spanish Imperative Intonation Revisited: Local Considerations. Linguistics, Berlin, 40, p. 347-374, 2002. 